\title{
Study of Manufacturers and Retailers Pricing under Dual Channel Mode-Based on Stackelberg Gamble
}

\author{
Siyuan Deng ${ }^{1}$ \\ ${ }^{1}$ Shandong University, Shandong University (WeiHai), WeiHai, Shandong, 264200 \\ hunter2011@foxmail.com
}

Keywords: Dual Channel Mode; Consumer Utility; Stackelberg Gamble; Equilibrium Pricing

\begin{abstract}
Manufacturers dual channel mode is accompanied by the birth of the Internet and the emergence of new sales environment, the retailers adhered to the traditional channels under this mode are often required to lower prices in order to cope with shocks. This article assumes market that only has one manufacturer and one retailer, establish consumer utility function including consumer loyalty factor. Firstly, deduce the traditional channels of only a single retailer balanced pricing, use Stackelberg gamble to deduce balanced pricing of manufacturers and retailers under dual channel mode. By comparing the two modes retailer balanced pricing, this paper finds retailers can take advantage of consumer loyalty of the brand to effectively resist the impact of the network channels instead of blindly cutting prices.
\end{abstract}

\section{Introduction}

With the birth of the 20th century, the Internet, the sale of goods changed from the traditional "manufacturers-retailers-consumers" channel to "manufacturers-consumer" and "manufacturers-retailers-consumers" double channel coexist. After the manufacturer into the network of sales channels, as retailers compete for any channel is sensitive, it will inevitably lead to their manufacturers and retailers to compete on the sales channel. Therefore, how to develop a reasonable commodity prices to maintain the stability of the entire supply chain under the e-commerce environment has become the most important decisions. For the study of a single network channels, Coughlan \& Anderson (2008) that the network is to allow consumers to fully understand the product through digital property, and further complete channel purchased. For dual channel mode, Balasubramanian (1998) was first established shopping model to study the pricing game one manufacturer and several retailers, we reached a different channels information released will produce differences, thereby affecting consumer choice , companies can reduce the impact of competition brought about by the channel control more market space. Lal \& Sarvary (1999) established in the paper a simple consumer utility function, draw energy consumers in the network channels and only through digital Attributes to understand its characteristics, likely to cause distortion of information, so the network channels consumer utility function intercept the image will be less than traditional channels. Chiang (2003) compared the two-channel model after model and traditional retailers believe in dual channel mode retailers will try to lower prices to stimulate sales, even if ultimately zero net sales, manufacturers will profit. The introduction of the network channels most significant effect is to increase sales productivity. Kumar \& Ruan (2006) and Kurata (2007) has established a linear demand function, examines the impact of dual-channel mode for different retailers, consumer loyalty obtained the impact on network channels is greater than traditional channels. Domestic scholars Chen Yun, Wang Huan-chen et al. (2006) use a two-stage game model to analyze the retailer has a dual channel mode when the optimal pricing and profits, obtained when the marginal utility of consumers resulting from network channels is not less than the traditional channels, Dual Channel optimal pricing with the expansion of the network channels decreases; when the marginal utility of the network channels is lower than traditional channels, only the extent of coverage of the network channels exceeds a critical value of its profit will exceed the traditional channels. 
In summary, the current study is to construct the consumer utility function and use of game model in the case of a manufacturer or retailer to introduce network channels, how to resolve their conflicts and to develop dual-channel equilibrium price. Although the study reaches some consensus, it has shortage of contradictions. In this paper, on the basis of previous studies made to extend, taking into account traditional consumer channels, network channels is greater than the marginal utility of consumers, build consumer utility function, and derive profit consumer demand function returns the dual-channel mode, by Game Stackelberg equilibrium price obtained and the quantitative calculation of the consumer when the retailer brand loyalty to what extent even in the face into the retail network channels do not have a sale, has practical significance.

\section{Stackelberg Gamble and Pricing Analysis under Dual Channel of Manufacturers and Retailers}

Consumer Utility Function. This article assumes that one of the most simple case, that only a manufacturer and a retailer, a manufacturer that is evenly distributed in the market consumers on a dual-channel supply chain wrapped, but because the information ravines and other obstacles manufacture, manufacturing Suppliers have to rely on traditional channels of information barriers and break through retailers sell to consumers. With the advent of network channels, manufacturers can select the network channels to reach consumers directly and sell products.

However, consumers can only be learned through the network channels of digital consumer product attributes, the result is often a different consumers to purchase the desired product, so the consumer utility function under the network channels are discounted (Lal \& Sarvary 1999), at the same time latency network channels to buy, consumers will also reduce utility function (Hess et al. 1996). Disadvantages are the advantages of traditional network channels channels, and such consumer loyalty to brand products, to bring the impact of utility function more pronounced (Kurata 2007).

Based on the above analysis, we establish the following consumer utility function:

$$
\left\{\begin{array}{c}
U_{t}=\beta V-P_{t} \\
U_{i}=V-T-P_{i}
\end{array}\right.
$$

Ui and Ut are utility function network channels and traditional channels of consumers, $\mathrm{Pi}$ and $\mathrm{Pt}$ are consumers on a dual-channel consumer purchase price of the same product, respectively, temporarily located here $P_{\mathrm{i}}<P_{\mathrm{t}}$. $\mathrm{V}$ is a consumer product utility estimates that consumers get maximum satisfaction from the product. T In this application Friberg and Ganslandt (2001) defined in its articles, namely $\mathrm{T}$ cost the consumer to buy the product through the network channels, consumers will choose the network channels when $\mathrm{T}>P_{\mathrm{i}}$.

The Basic Model Assumptions. Hypothesis 1: Let consumers are uniformly distributed on the size of the market 1 .

Hypothesis 2: Suppose V in $[0,1]$ distribution that consumers estimate the effectiveness of the product does not exceed the value of its currency, but it will not have a negative effect.

Hypothesis 3: $\mathrm{T}>P_{\mathbb{i}}$, which is based on existing literature and assumptions.

Hypothesis 4: Consumer Product utility estimates V traditional channels and consumer loyalty positive correlation coefficient, $\beta>1$.

Hypothesis 5: because wholesale prices are manufacturer and retailer in the negotiations prior to the completion of the drawn channel, change the channel while not change, and therefore assumed to be constant $\mathrm{g}$, while $\mathrm{g}>P_{\mathrm{i}}$, that is, less than the wholesale price retail sales network price, otherwise the retailers will abandon traditional channels.

Hypothesis 6: Suppose the traditional channel retailers to get merchandise cost is C, the product from the manufacturer to the retailer intermediate process all costs, including product prices and storage and so on.

Hypothesis 7: The two sides of Stackelberg Gamble based on complete information. 
Based on the consumer utility function and assume that we will process simulation game were from a single channel and dual channel respectively tradition.

Pricing Analysis of a Single Traditional Channels. Only the traditional channels, the decisions consumers to buy products is based on $U_{t}=\beta V-P_{t}$ utility function, $U_{t}=\beta V-P_{t}>0$ consumers will buy the product, $\mathrm{V}=\frac{P_{t}}{\beta} \quad$ consumer indifference point. Therefore, consumers end up in the $\frac{P_{t}}{\beta}<\mathrm{V}$ $<1$ range the initial purchase decision. Because the market size is 1 , so we can get a single traditional channels consumers demand function:

$$
\mathrm{Q}_{\mathrm{t} 1}=1-\frac{\mathrm{P}_{\mathrm{t}}}{\beta}
$$

From this we can draw at this manufacturer and retailer profits are as follows:

$$
\begin{aligned}
& \pi_{m}\left(P_{t}\right)=(g-C) Q_{t 1}=(g-C)\left(1-\frac{P_{t}}{\beta}\right) \\
& \pi_{d}\left(P_{t}\right)=\left(P_{t}-g\right) Q_{t 1}=\left(P_{t}-g\right)\left(1-\frac{P_{t}}{\beta}\right)
\end{aligned}
$$

The wholesale price is determined, retailers set prices to maximize profits based on:

$$
\frac{\partial \pi_{d}}{\partial P_{t}}=0, \quad P_{t}^{*}=\frac{\beta+g}{2}
$$

Take $P_{t}^{*}$ into $\pi_{m}, \pi_{d}$ and $Q_{t 1}$ :

$$
\begin{gathered}
\pi_{m}=(g-c) \frac{\beta+g}{2 \beta} \\
\pi_{d}=\left(\frac{\beta+g}{2}-g\right) \frac{\beta+g}{2 \beta} \\
Q_{t 1}^{*}=\frac{\beta+g}{2 \beta}
\end{gathered}
$$

Pricing Manufacturers Dual Channel Mode Analysis. With the development of electronic commerce, assuming manufacturers into the network of sales channels, and traditional retail channels together constitute dual channel mode. Let the network channel consumer demand , priced ; consumer demand for the traditional channels $Q_{t}$, priced at $V \geq \frac{P_{t}}{\beta}$.

When consumers buy from traditional sources need to be met $\beta V \geq P_{t}$ : that. $V \geq \frac{P_{t}}{\beta}$

When consumers buy from the network channels need to meet: $V \geq \mathrm{T}+P_{\mathrm{i}}$

When $\beta V-P_{\mathrm{t}} \geq V-T-P_{\mathrm{i}}$, instant $V \geq \frac{P_{\mathrm{t}}-P_{\mathrm{i}}-T}{\beta-1}$, traditional channels for consumers than network channels, network channels otherwise superior to the traditional channels.

When traditional channels than network channels, namely $\frac{P_{t}}{\beta}>T+P_{i}$ consumers get from traditional channels is greater than the utility of the network channels, instant $\frac{P_{\mathrm{t}}-P_{\mathrm{i}}-T}{\beta-1}>\frac{P_{\mathrm{t}}}{\beta}$, can be obtained by mathematical calculations, shown in Figure 2, when the utility[0,T+P $]$ is located at $\left[T+P_{i}, \frac{P_{t}-P_{i}-T}{\beta-1}\right]$ the consumers will not buy the product, it is located at the consumers will choose the network channels, $\left[\frac{P_{\mathrm{t}}-P_{\mathrm{i}}-T}{\beta-1}, 1\right]$ will choose the traditional channels. 


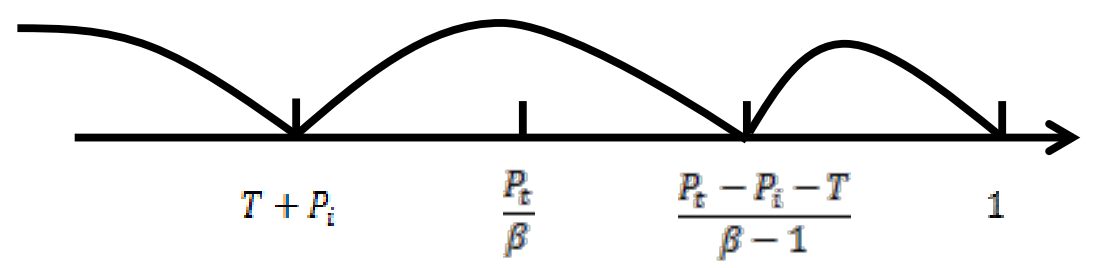

Fig. 2 A schematic view of consumer choice

When the network channels is superior to traditional channels, namely $\frac{P_{t}}{\beta}<T+P_{\tilde{i}}$, by mathematical calculations $\frac{P_{t}-P_{i}-T}{\beta-1}<\frac{P_{t}}{\beta}$, shown in Figure 3, when $\left[\frac{P_{t}}{\beta}, 1\right]$ the utility consumers will choose to purchase through traditional channels, $\left[0, \frac{P_{t}}{\beta}\right]$ consumers will not buy.

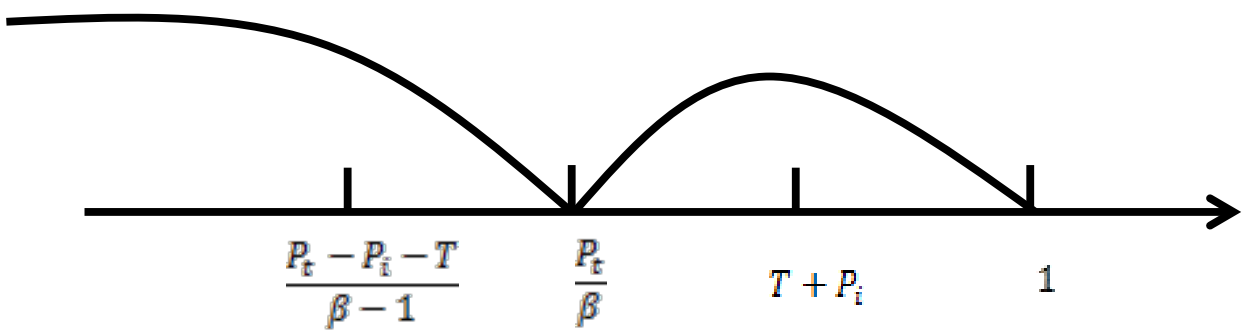

Fig.3 Schematic consumer choice

From the above analysis we can draw the consumer demand function separately for traditional channels and network channels:

$$
\begin{gathered}
Q_{t}=\left\{\begin{array}{c}
1-\frac{P_{t}-P_{i}-T}{\beta-1}, \frac{P_{t}}{\beta} \geq T+P_{i} \\
1-\frac{P_{t}}{\beta}, \frac{P_{t}}{\beta}<T+P_{i}
\end{array}\right. \\
Q_{i}=\left\{\begin{array}{c}
\frac{P_{t}-P_{i}-T}{\beta-1}-\left(T+P_{i}\right), \frac{P_{t}}{\beta} \geq T+P_{i} \\
0, \frac{P_{t}}{\beta}<T+P_{i}
\end{array}\right.
\end{gathered}
$$

From this we can draw profit function under dual channel manufacturer of manufacturers and retailers:

Further calculations can be drawn:

$$
\begin{aligned}
\pi_{m} & =P_{i} Q_{i}+\left(g-C_{,}\right. \\
\pi_{d} & =\left(P_{t}-g\right) Q_{t}
\end{aligned}
$$

$$
\begin{gathered}
\pi_{m}=\left\{\begin{array}{c}
\left(P_{i}-g+C\right) \frac{P_{t}-P_{i}-T}{\beta-1}-P_{i}-P_{i}^{2}+g-C, \frac{P_{t}}{\beta} \geq T+P_{i} \\
(g-C)\left(1-\frac{P_{t}}{\beta}\right), \frac{P_{t}}{\beta}<T+P_{i}
\end{array}\right. \\
\pi_{d}=\left\{\begin{array}{c}
\left(P_{t}-g\right)\left(1-\frac{P_{t}-P_{i}-T}{\beta-1}\right), \frac{P_{t}}{\beta} \geq T+P_{i} \\
\left(P_{t}-g\right)\left(1-\frac{P_{t}}{\beta}\right), \frac{P_{t}}{\beta}<T+P_{i}
\end{array}\right.
\end{gathered}
$$

Because retailers and manufacturers access to distribution channels, so although manufacturers use network channels to establish a competitive relationship with retailers, but it is still pricing in 
terms of retail pricing passive response. Therefore, the retailer Stackelberg Gamble in Leader position, the manufacturer is Follower position.

At that time $\frac{P_{t}}{\beta}<T+P_{\mathrm{i}}$, dual channel mode and single traditional channels manufacturers and retailers profit function the same, so this will not be repeated here. Here focuses on the situation $\frac{P_{t}}{\beta} \geq T+P_{i}$ :

$$
\begin{gathered}
\pi_{m}=\left(P_{i}-g+C\right) \frac{P_{t}-P_{i}-T}{\beta-1}-P_{i}-P_{i}^{2}+g-C \\
\pi_{d}=\left(P_{t}-g\right)\left(1-\frac{P_{t}-P_{i}-T}{\beta-1}\right)
\end{gathered}
$$

Manufacturer assume price retailer has been set, so, reflected function $\frac{\partial \pi_{m}}{\partial P_{i}}=0$ :

$$
P_{i}=\frac{P_{t}-T+g-C-\beta+1}{2 \beta}
$$

It follows that the retailer's profit function:

$$
\pi_{\mathrm{d}}=\left(\mathrm{P}_{\mathrm{t}}-\mathrm{g}\right)\left(1-\frac{\mathrm{P}_{\mathrm{t}}(2 \beta+1)-\beta(2 \mathrm{~T}+1)-\mathrm{T}+\mathrm{g}-\mathrm{C}+1}{2 \beta(\beta-1)}\right)
$$

Order $\frac{\sigma_{\pi_{d}}}{\partial P_{t}}=0$ to obtain the best price equilibrium retailers:

$$
\mathrm{P}_{\mathrm{t}}^{*}=\frac{2 \beta^{2}-\beta(3+2 \mathrm{~T}-2 \mathrm{~g})+\mathrm{T}+\mathrm{C}-1}{4 \beta+2}
$$

$P_{\mathrm{i}}$ be substituted into the expression derived manufacturer of the network channels equilibrium Best Price:

$$
\mathrm{P}_{\mathrm{i}}^{*}=\frac{-2 \beta^{2}-\beta(1+6 \mathrm{~T}-6 \mathrm{~g}+4 \mathrm{C})-\mathrm{T}-\mathrm{C}+2 \mathrm{~g}+1}{8 \beta^{2}+4 \beta}
$$

The profit function $P_{t}^{*}$ and $P_{i}^{*}$ on behalf of manufacturers and retailers will be to obtain a balanced profits of both:

$$
\begin{gathered}
=-\frac{4 \beta^{4}+(1+6 \mathrm{~T}-6 \mathrm{~g}+4 \mathrm{C})\left[\begin{array}{c}
\beta^{2}(1+6 \mathrm{~T}-6 \mathrm{~g}+4 \mathrm{C}+4 \beta)+ \\
\beta(\mathrm{T}+\mathrm{C}-2 \mathrm{~g}+1)
\end{array}\right]+(2 \mathrm{~g}-\mathrm{T}-\mathrm{C}+1)\left(\begin{array}{c}
4 \beta+2 \mathrm{~g} \\
-\mathrm{T}-\mathrm{C}+1
\end{array}\right)}{\left(8 \beta^{2}+4 \beta\right)^{2}} \\
\pi_{\mathrm{d}}^{*}=\frac{2 \beta^{2}-\beta(3+2 \mathrm{~T}+2 \mathrm{~g})+\mathrm{T}+\mathrm{C}-2 \mathrm{~g}-1}{4 \beta+2} \\
\cdot \frac{4 \beta^{3}-\beta^{2}(4 \mathrm{~g}-12 \mathrm{~T})-\beta(4 \mathrm{~T}-6 \mathrm{~g}+6 \mathrm{C})-\mathrm{T}-\mathrm{C}+2 \mathrm{~g}+1}{\left(8 \beta^{2}+4 \beta\right)(\beta-1)}
\end{gathered}
$$

Dual channel Mode based on Stackelberg Gamble. From the above derivation we get a balanced pricing single traditional channels:

$$
\begin{gathered}
\mathrm{P}_{\mathrm{t}}^{*}=\frac{\beta+\mathrm{g}}{2} \\
\mathrm{P}_{\mathrm{t}}^{*}=\frac{2 \beta^{2}-\beta(3+2 \mathrm{~T}-2 \mathrm{~g})+\mathrm{T}+\mathrm{C}-1}{4 \beta+2} \\
\mathrm{P}_{\mathrm{i}}^{*}=\frac{-2 \beta^{2}-\beta(1+6 \mathrm{~T}-6 \mathrm{~g}+4 \mathrm{C})-\mathrm{T}-\mathrm{C}+2 \mathrm{~g}+1}{8 \beta^{2}+4 \beta}
\end{gathered}
$$

In order to analyze comparative manufacturers into the network before and after the retailer channel balanced pricing change and the level of manufacturers and retailers in the dual channel mode equilibrium pricing, we derive the above formula for the difference: 


$$
\begin{gathered}
\frac{\beta+\mathrm{g}}{2}-\frac{2 \beta^{2}-\beta(3+2 \mathrm{~T}-2 \mathrm{~g})+\mathrm{T}+\mathrm{C}-1}{4 \beta+2}=\frac{\mathrm{T}+\mathrm{C}+\mathrm{g}-1-\beta(4+2 \mathrm{~T})}{4 \beta+2} \\
\frac{2 \beta^{2}-\beta(3+2 \mathrm{~T}-2 \mathrm{~g})+\mathrm{T}+\mathrm{C}-1}{4 \beta+2}-\frac{-2 \beta^{2}-\beta(1+6 \mathrm{~T}-6 \mathrm{~g}+4 \mathrm{C})-\mathrm{T}-\mathrm{C}+2 \mathrm{~g}+1}{8 \beta^{2}+4 \beta} \\
\frac{\mathrm{T}+\mathrm{C}-2 \mathrm{~g}-1+8 \beta^{3}-\beta^{2}(4+4 \mathrm{~T}-4 \mathrm{~g})+\beta(8 \mathrm{~T}-6 \mathrm{~g}+6 \mathrm{C}-1)}{(4 \beta+2) 2 \beta}
\end{gathered}
$$

First, we can see that in dual channel mode, then $T>\frac{1+4 \beta-c-g}{1-2 \beta}$ if it means even $1+4 \beta-\mathrm{C}-\mathrm{g}<0$ in dual-channel mode Retailers balanced pricing may not necessarily be lower than when pricing a single traditional channels, and even higher than the latter. The math formula can be obtained:

$$
\beta>\frac{C+g-1}{4}
$$

Since the sum of the $\mathrm{C}$ on behalf of manufacturers, transportation, storage products and other costs, and $\mathrm{g}$ on behalf of the retailer to get wholesale price, including the sum of the cost price and wholesale profits of manufacturers, which also includes most of the transport and products storage costs, so $\mathrm{C}$ and g can be regarded as an approximate value, which can be written on the formula:

$$
\beta>\frac{2 g-1}{4}
$$

The Economic Significance of the formula contained in that: in dual channel mode, the retailer is not only blindly lower prices to expand market demand response into the network channels. Because brand loyalty for retailers on the traditional channels of influence is large, so retailers can also consider increasing consumer acceptance of the brand quality. When consumers because of the brand recognition retailers willing to pay half of the wholesale price for a product, even if the introduction of the network channels manufacturers, retailers can not unilaterally reduce the price, while loyal consumers and retailers coefficient in dual channel mode can fix the equilibrium price is directly proportional.

\section{Conclusion}

In this paper, the equilibrium price under manufacturer dual channel mode manufacturers and retailers were investigated and studied the possibility of retailers use consumer brand loyalty shock to response to network channels. This paper assumes that only one manufacturer and a retailer, the two were using the Internet and traditional sales channels, in which case the equilibrium price is not always lower than traditional retailers, but should consider the retailer brand loyalty. When the loyalty to the brand recognition exceeds a critical value, retailers cannot lower the equilibrium price. This conclusion breaks the normal circumstance that when a manufacturer makes the network channels into the sales cycle, retailers will cut prices to boost sales.

\section{References}

[1] Balasubramanian S. Mail Versus Mall: A Strategic Analysis of Competition Between Direct Marketers and Conventional Retailers. Marketing Science, 1998 17(3): 181-195

[2] Chiang W K, Chhajed D, Hess J D. Direct Marketing, Indirect Profits: A Strategic Analysis of Dual-Channel Supply-Chain Design. Management Science, 2003, 49(1): 1-20

[3] Kumar N, Ruan R. On Manufacturers Complementing the Traditional Retail Channel with A Direct Online Channel. Quantitative Marketing and Economics, 2006, 4(3): 289-323

[4] Kurata H, Yao D Q, Liu J J. Pricing Policies Under Direct Vs. Indirect Channel Competition and National Vs. Store Brand Competition. European Journal of Operational Research, 2007, 180(1): 262-281 
[5] Lal R, Sarvary M. When and How Is the Internet Likely to Decrease Price Competition. Marketing Science, 1999, 18(4): 485-503

[6] S.Z. Chen, X.Z. Kai, Y.C. Tang. Dual Pricing Supply Chain Distribution Channel. Statistics and Decision, 2007 (2): 29-31

[7] Y. Chen, H.C. Wang, H.Z. Shen. Pricing Strategy Dual-Channel Retailer Internet Environment. Management Engineering, 2008,22 (1): 34-39

[8] Y.P. Liu, X.Y. Chen. Impact of Electronic Commerce on the Modern Enterprise Growth Commercial Research, 2004 (12): 164-167

[9] X.M. Chen, The Pricing Strategy of E-Commerce Background Dual Channel Manufacturer. Shandong University, 2014

[10] N.N. Yan, Y. Huang, Bing Electronic Market Environment Supply Chain Dual-Channel Game Models.China Management Science, 2007,15 (3): 98-102

[11] L.M. Yang. Enhance The Role of E-Commerce on The Competitiveness of Enterprises. Commercial Research, 2004 (11): 174-177 